\title{
Inadvertent inflation of Foley catheter balloon with contrast: an error that caused unnecessary apprehensions
}

\author{
Siddharth Pandey, Deepanshu Sharma, Gaurav Garg, Satyanarayan Sankhwar
}

Department of Urology, King George's Medical University, Lucknow, Uttar Pradesh, India

\section{Correspondence to Dr Siddharth Pandey, sid1420@gmail.com}

Accepted 4 April 2018

\section{DESCRIPTION}

A 30-year-old male patient underwent percutaneous nephrolithotomy (PCNL) for a $3.5 \mathrm{~cm}$ right renal calculus. As per our institutional protocol he underwent a check X-ray the next day. The relatives of the patient immediately came to us asking whether some residual fragments of the calculus were there in the urinary bladder. When we reviewed the X-ray film, there was a radioopaque shadow with a smooth contour in the region of urinary bladder. On careful examination this shadow was continuous with a radioopaque line along the Foley catheter (figure 1). We immediately removed the Foley catheter and did another check X-ray. The shadow had disappeared. We then realised that the catheter's balloon was inflated with contrast solution prepared for fluoroscopy-guided puncture during PCNL. We acknowledged this error to the patient and his relatives and explained them how sorry we were for their anxiety, following which they were relieved that it was the Foley catheter bulb and not residual stones.

We usually prepare a contrast solution for puncture during PCNL with a 1:3 dilution with sterile water. The appearance of the Foley catheter balloon inflated with contrast was similar to a round vesical calculus and that caused

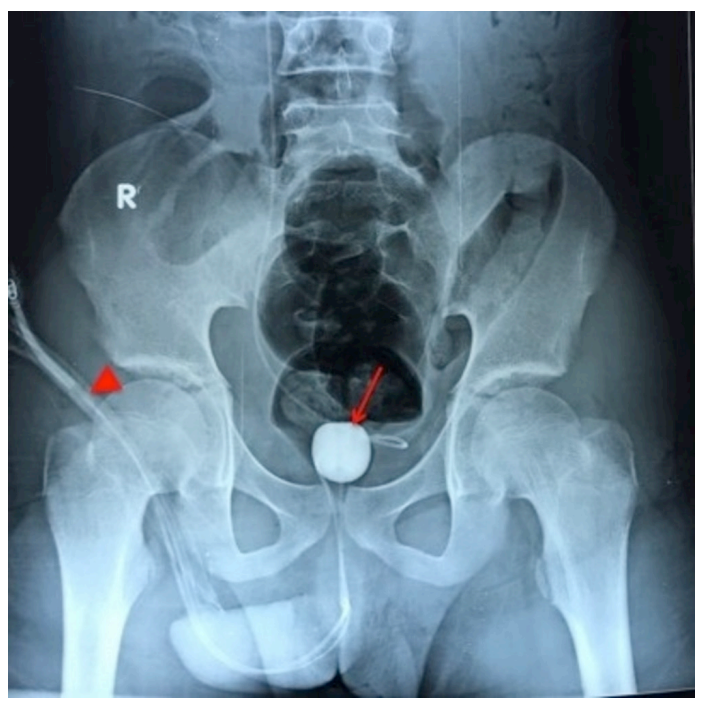

Garg G, et al. BMJ Case Rep Published Online First: [please include Day Month Year]. doi:10.1136/bcr-2018 225153 apprehension in the patient's mind that was relieved on doing the check X-ray after removal of the Foley catheter. Access into the pelvicalyceal system (PCS) for PCNL is usually done via fluoroscopy-guided puncture with the patient in prone position. ${ }^{1}$ A ureteric catheter is placed before this so that the contrast solution can be instilled into the PCS for identifying the calyceal anatomy and also it can be used to flush small fragments of calculus during PCNL. A Foley catheter is also placed along with the ureteric catheter to secure it. The ureteric catheter is usually removed immediately after PCNL and the Foley catheter is retained, and removed later in the ward. Ideal solution for filling the balloon of a Foley catheter is sterile water as ionic solutions can cause crystallisation and subsequent difficulty in catheter removal. ${ }^{2}$ Other authors have proposed that $0.9 \%$ saline and $1.5 \%$ glycine can also be used without any risk of complications. ${ }^{3}$ We usually use sterile water or $0.9 \%$ saline that is kept in a separate sterile bowl for this purpose, but in this case the diluted contrast solution was mistaken for sterile water and instilled into the Foley catheter balloon. The contrast solution and sterile water were kept in separate sterile bowls but if they would have been kept in separate sized syringes it could have prevented this error. Also contrast is more viscous we could have differentiated it from sterile water

Learning points

- One should be careful during urological procedures where contrast is commonly used, as the solution is transparent and visually cannot be differentiated from $0.9 \%$ saline used for flushing stones and other transparent solutions.

- This error can be avoided by keeping the contrast solution in separate sized syringes, also the operator can feel the resistance in the syringe during inflation and stickiness after it due to the greater viscosity of contrast as an indirect indicator of this error.

- If inadvertently contrast has been used for inflating the Foley catheter balloon it can be identified on X-ray with certain signs such as a radio-opaque line on the catheter due to contrast in the inflation channel and a smooth round contour of the radio-opaque Foley catheter bulb. 
by the resistance in the syringe while inflating and stickiness after inflating it, which we missed. Contrast solution being more viscous can clog the channel for balloon inflation. In our case, it did not happen because we removed the catheter on the next day and it was a diluted contrast solution.

Contributors SP conceived the case report. SP and DS were major contributors towards writing the manuscript. GG, SS and SP treated the patient and also interpreted the patient data. SP and SS were involved in the review. All authors read and approved the final manuscript.

Funding The authors have not declared a specific grant for this research from any funding agency in the public, commercial or not-for-profit sectors.

Competing interests None declared.
Patient consent Obtained.

Provenance and peer review Not commissioned; externally peer reviewed.

(c) BMJ Publishing Group Ltd (unless otherwise stated in the text of the article) 2018. All rights reserved. No commercial use is permitted unless otherwise expressly granted.

\section{REFERENCES}

1 Ray AA, Chung DG, Honey RJ. Percutaneous nephrolithotomy in the prone and prone-flexed positions: anatomic considerations. J Endourol 2009;23:1607-14.

2 Gonzalgo ML, Walsh PC. Balloon cuffing and management of the entrapped Foley catheter. Urology 2003;61:825-7.

3 Huang JG, Ooi J, Lawrentschuk N, et al. Urinary catheter balloons should only be filled with water: testing the myth. BJU Int 2009;104:1693-5.

Copyright 2018 BMJ Publishing Group. All rights reserved. For permission to reuse any of this content visit http://group.bmj.com/group/rights-licensing/permissions.

BMJ Case Report Fellows may re-use this article for personal use and teaching without any further permission.

Become a Fellow of BMJ Case Reports today and you can:

- Submit as many cases as you like

- Enjoy fast sympathetic peer review and rapid publication of accepted articles

- Access all the published articles

- Re-use any of the published material for personal use and teaching without further permission

For information on Institutional Fellowships contact consortiasales@bmjgroup.com

Visit casereports.bmj.com for more articles like this and to become a Fellow 